\title{
(2) OPEN ACCESS \\ Pleomorphic carcinoma of the trachea after chemoradiotherapy for laryngeal cancer
}

\author{
Hirotaka Saikawa, ${ }_{1}^{1}$ Noriyuki Uesugi, ${ }^{2}$ Tamotsu Sugai, ${ }^{2}$ Makoto Maemondo ${ }^{1}$
}

'Division of Pulmonary Medicine, Allergy, and Rheumatology, Department of Internal Medicine, Iwate Medical University, Iwate, Japan ${ }^{2}$ Department of Molecular Diagnostic Pathology, Iwate Medical University, Iwate, Japan

\section{Correspondence to}

Professor Makoto Maemondo; maemondo-ma693@aioros. ocn.ne.jp

Accepted 30 September 2020

\section{SUMMARY \\ A 66-year-old male patient who had received chemoradiotherapy (CRT) for laryngeal cancer 2 years ago visited a local doctor complaining of dyspnoea and wheezing. CT scan showed narrowing of the trachea caused by a tumour. We intubated the trachea over the tumour using a bronchoscope. A week later, the truncated tracheal tumour obstructed the tracheal tube, compromising the patient's breathing. We removed the obstructed tube and inserted a new one. We submitted the tissue from the tube to a pathologist. Histopathological diagnosis was pleomorphic carcinoma, a subtype of sarcomatoid carcinoma. The mechanism of epithelial-mesenchymal transition (EMT) occurring after CRT was detected in the tumour. Because he had undergone CRT for laryngeal cancer, surgery was not indicated, and we started radiation therapy. Sarcomatoid carcinomas including pleomorphic carcinoma of the trachea are extremely rare, with few reported cases, and EMT is associated with this histological type and CRT.}

\section{BACKGROUND}

Primary tracheal tumours are rare. One report found only two primary tracheal tumours detected in 9000 autopsy cases. ${ }^{1}$ Pleomorphic carcinoma, a subtype of sarcomatoid carcinoma, is rare in any organ. To date, only three cases of sarcomatoid carcinoma in the trachea have been reported. ${ }^{2-4}$ Epithelial-mesenchymaltransition (EMT) is related to metastasis and resistance to therapy. ${ }^{5}$ Generally, surgical resection is considered useful for tracheal tumours. We searched the literature, but did not find any cases of a primary tracheal tumour developing after CRT for a head and neck tumour. We report a case of rare primary tracheal tumour related to EMT.

\section{CASE PRESENTATION}

A 66-year-old male patient received chemoradiotherapy (CRT) (intensity modulated radiation therapy: IMRT, $66 \mathrm{~Gy} / 33 \mathrm{Fr}$, and docetaxel) for squamous cell carcinoma of the larynx 2 years before this event. He was a former smoker with a history of two cerebral haemorrhages. He developed dyspnoea and wheezing lasting about a month, and visited a local otolaryngologist. His vital signs were normal. On auscultation, wheezing was heard. The doctor suspected bronchial asthma, and performed blood tests and a CT scan to exclude other diseases. Blood tests showed no significant abnormal findings, including tumour markers. The CT scan showed a tumour causing narrowing of the trachea, so the doctor consulted a respiratory physician in the same facility. The situation was considered life-threatening and the patient was intubated using a bronchoscope and placed on a mechanical ventilator. The tumour obstructing the trachea was identified using a bronchoscope (figure 1). The large tumour had a stalk and bled easily. The next day, the patient became feverish and developed hypoxaemia. Bilateral consolidations of the base of the lungs were observed by chest X-ray. Blood tests showed elevated inflammatory markers including C-reactive protein. The patient was diagnosed with ventilator-associated pneumonia (VAP) and antibiotic treatment by intravenous drip of tazobactam/piperacillin $13.5 \mathrm{~g} /$ day was initiated. Four days later, the patient was sent to our hospital for intensive treatment for VAP and treatment of the tracheal tumour.

\section{INVESTIGATIONS}

CT scan showed the tumour obstructing the trachea (figure 2). We initially considered the tumour as a metastasis of laryngeal cancer previously treated, but the location was near the second tracheal cartilage and different from location of the first malignancy. A week later, the truncated part of tracheal tumour had obstructed the tracheal tube, compromising his breathing. We exchanged the tube and submitted the tissue truncated in the tube to a pathologist. We considered the part of tumour was accidentally resected by tracheal tube sliding. Histopathological findings (H\&E staining) of the tumour showed both an epithelial and a spindle cell component (mesenchymal component) in the same specimen (figure 3). In immunohistochemical staining, the epithelial component stained epithelial markers such as E-cadherin, and the mesenchymal component stained mesenchymal markers such as Zeb-1 and Twist. In the part of the epithelial component in contact with the mesenchymal component, the transitional component was observed. In the mesenchymal component (spindle cell component), E-cadherin was negative, and Zeb-1, Twist and Snail/Slug were positive, so EMT was suspected (figure 4). Expression of Ki-67, a marker of cell proliferation, was similar in both component. All the results of immunohistochemical staining are shown in table 1.

\section{DIFFERENTIAL DIAGNOSIS}

At this point, we had considered the tumour to be tracheal recurrence of laryngeal cancer, but the pathological type and location was different. Pathological findings showing the epithelial and spindle cell components were decisive in diagnosis. The spindle cell component was greater than $10 \%$, and from this result we diagnosed the 


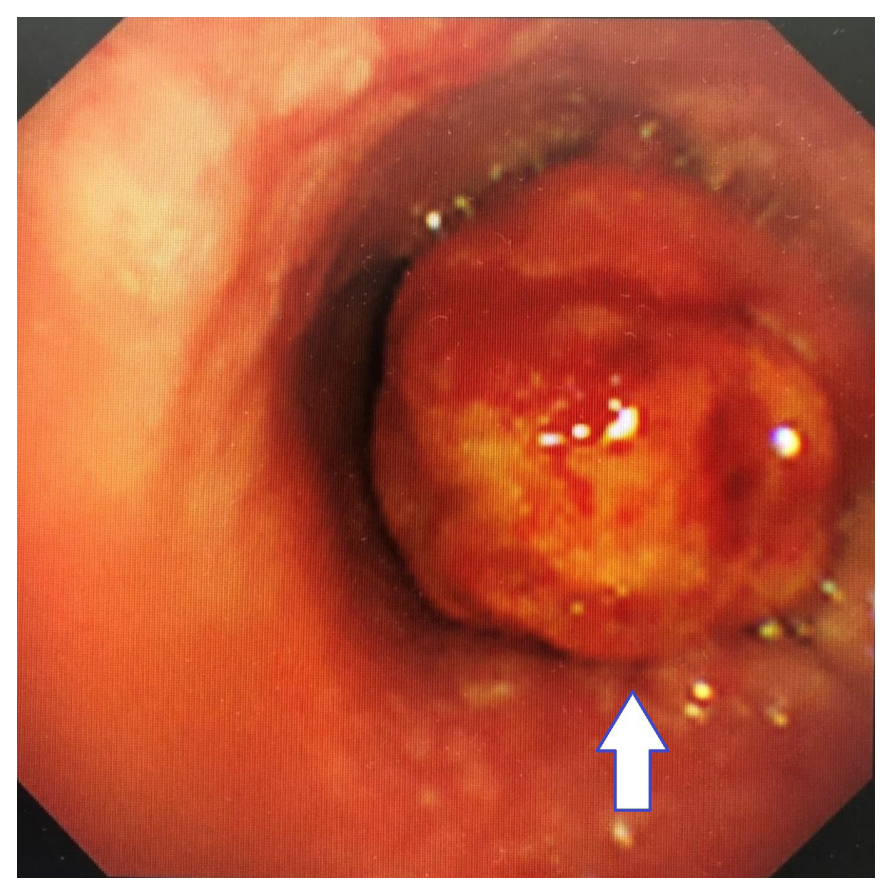

Figure 1 Bronchoscopic findings of the tracheal tumour. The tumour narrowed the trachea and was prone to bleeding.

tumour as pleomorphic carcinoma, a subtype of sarcomatoid carcinoma.

\section{TREATMENT}

We continued antibiotic treatment for VAP and performed a tracheostomy 10 days after re-intubation. The tumour was located near the second tracheal cartilage and we made a tracheotomy at the third tracheal cartilage to avoid the tumour. We considered bronchoscopic resection for remaining tracheal tumour, but decided not to do it because the tumour was prone to bleeding and the stem was too large and we understand that bronchoscopic resection of tracheal tumour is at high risk and is generally performed only in the operating room under general anaesthesia for patients in good general condition. Although we considered the option of complete resection of the tumour, we chose RT through the tumour board meeting because surgery after CRT for laryngeal cancer would have entailed an increased risk of complications including necrosis and rupture of previously irradiated structures. RT (IMRT, $60 \mathrm{~Gy} / 30 \mathrm{Fr}$ ) was

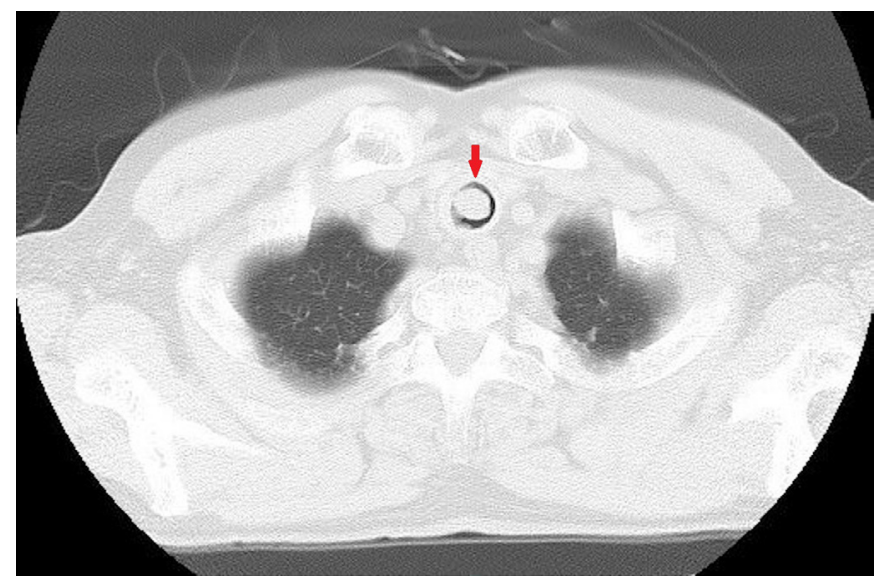

Figure 2 CT scan showing narrowing of the trachea.

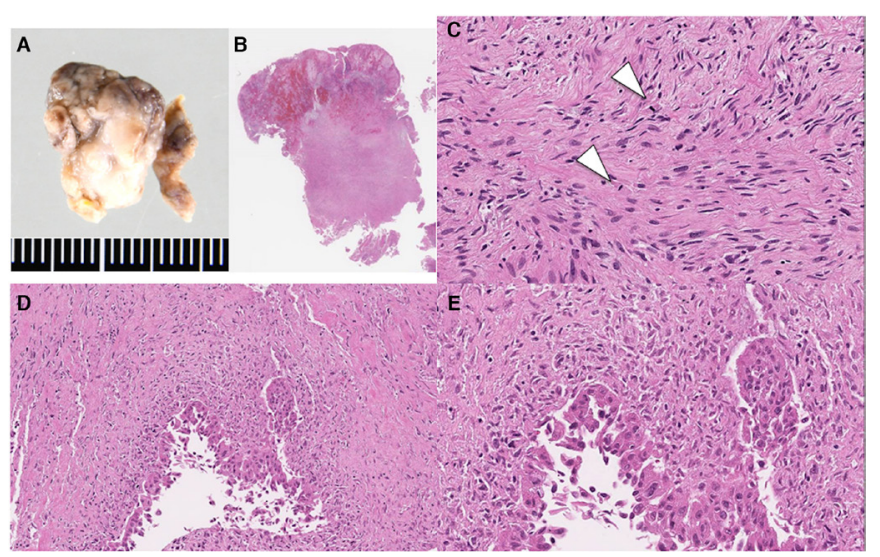

Figure 3 Macroscopic findings (a) showed a tumour $13 \mathrm{~mm} \times 10$ $\mathrm{mm}$ in size. Histopathological findings (H\&E staining) of the tumour at lower magnification (b) show the upper level of the figure filled with the necrotic component. In the spindle cell component (c), arrows indicate typical spindle cells. The transitional component ( $d$ and e) shows the epithelial component in contact with the mesenchymal component.

performed and avoided damage of normal tissues around the tumour as much as possible.

\section{OUTCOME AND FOLLOW-UP}

Two months have passed since he received RT and the patient is alive. However, we cannot yet evaluate the outcome of treatment because there was no evaluable lesion. In the future, we will evaluate the outcome based on recurrence and metastasis of the tumour, and survival.

\section{DISCUSSION}

Tracheal tumours cause varying degrees of dyspnoea depending on tumour size, and are often misdiagnosed as bronchial asthma or chronic obstructive pulmonary disease. ${ }^{6}$ In this case, because the patient received CRT for laryngeal cancer 2 years before

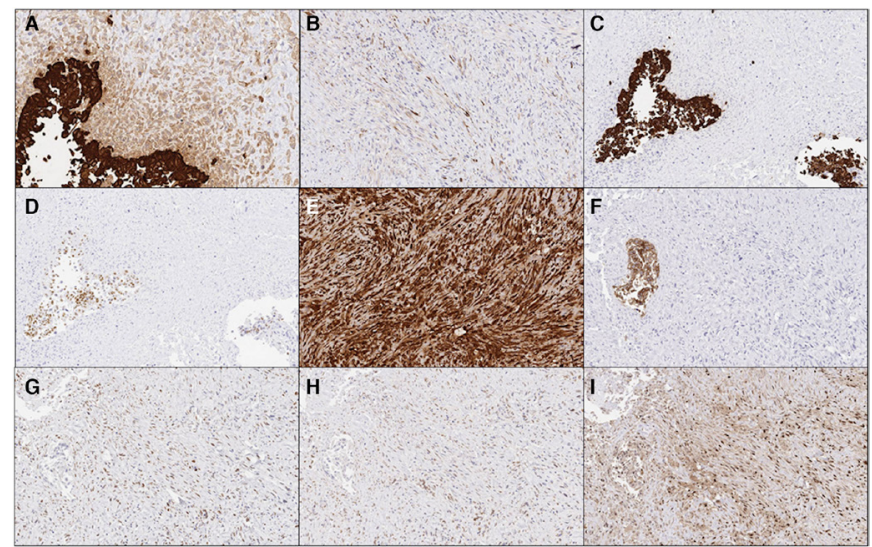

Figure 4 Immunohistochemical staining showed that the epithelial component was positive for CK AE1/AE3 but the mesenchymal component was negative (a). The spindle cell component (b) was negative for CK AE1/AE3. The epithelial component was positive for CK $5 / 6$ but the mesenchymal component was negative (c). The epithelial component was positive for p40 but the mesenchymal component was negative (d). The spindle cell component (e) was positive for vimentin (e). The epithelial component was positive for E-cadherin but the mesenchymal component was negative. Zeb-1 (g), Twist (h) and Snail/ Slug (i) were positive in only the mesenchymal component. 
Table 1 Immunohistochemical staining findings

\begin{tabular}{|c|c|c|c|c|c|c|}
\hline Antibody & Clone & Source & Dilution & Pretreatment & $\begin{array}{l}\text { Result of Epithelial } \\
\text { component }\end{array}$ & $\begin{array}{l}\text { Result of Spindle cell } \\
\text { component }\end{array}$ \\
\hline CK AE1/AE3 & AE1/AE3 & Dako & $1: 200$ & MW & positive & weak positive \\
\hline EMA & E29 & Dako & $1: 100$ & None & positive & negative \\
\hline CK5/6 & D5/16B4 & Dako & $1: 100$ & MW & positive & negative \\
\hline E-cadherin & $4 \mathrm{~A} 2 \mathrm{C} 7$ & Zymed Laboratory & $1: 5$ & MW & positive & negative \\
\hline p40 & $\mathrm{BC} 28$ & Bio Care Medical & $1: 80$ & None & positive & negative \\
\hline p63 & $4 \mathrm{~A} 4$ & Nichilei & $1: 2$ & MW & positive & negative \\
\hline Vimentin & Vim3B4 & Dako & $1: 200$ & MW & negative & positive \\
\hline Desmin & D33 & Dako & $1: 100$ & None & negative & negative \\
\hline S-100 & polyclonal & Dako & Ready to use & MW & negative & negative \\
\hline Muscle actin & HHF35 & Enzo Diagnostics & $1: 100$ & None & negative & negative \\
\hline alfa-SMA & $1 \mathrm{~A} 4$ & Dako & $1: 100$ & None & negative & positive \\
\hline CD34 & NU-4A1 & Nichilei & $1: 100$ & MW & negative & negative \\
\hline KIT & polyclonal & Dako & $1: 100$ & MW & negative & negative \\
\hline $\mathrm{Bcl}-2$ & 124 & Dako & $1: 10$ & MW & negative & negative \\
\hline Zeb-1 & polyclonal & SIGMA & $1: 50$ & MW & negative & positive \\
\hline Twist & Twiat2C1a & Abcam & $1: 50$ & MW & negative & positive \\
\hline Snail/Slug & polyclonal & Cell Signalling & $1: 80$ & MW & negative & positive \\
\hline Ki-67 & MIB-1 & Dako & $1: 50$ & MW & $22.60 \%$ & $24.00 \%$ \\
\hline TP53 & DO-7 & Novocastra & $1: 100$ & MW & negative & negative \\
\hline
\end{tabular}

this episode, we suspected a metastatic tumour originating from laryngeal cancer. However, the pathological type of the tracheal tumour was different from that of the previous laryngeal cancer. The tracheal tumour was diagnosed as pleomorphic carcinoma, a subtype of sarcomatoid carcinoma. Furthermore, tracheal metastasis of laryngeal cancer is extremely rare, and metastatic tracheal tumours generally originate from breast cancer, colorectal cancer or renal cancer. ${ }^{7}$ Histopathological findings in this case demonstrated the transitional component (the epithelial and mesenchymal component), and we concluded that EMT had developed in this tumour. EMT has been studied extensively relating to mechanisms of cancer metastasis and recurrence. ${ }^{89}$ At the transcriptional level, E-cadherin is repressed by a number of E-cadherin transcriptional repressors (EcTRs), including Zeb-1, Zeb-2, Snail/Slug, E12/E47 and Twist. Expression of these EcTRs in tumour epithelial cells is inversely correlated with E-cadherin expression and associated with increased invasiveness/metastasis and poorer clinical prognosis. ${ }^{10}$ The expression of EcTRs results in repression of the epithelial phenotype and promotion of EMT. ${ }^{11}$ EcTRs are present in mesenchyme and repress transcription of E-cadherin and induce to mesenchymal feature. One report studied the relationship between sarcomatoid carcinoma and EMT, and this case showed one of the typical patterns of EMT. $^{12}$ However, no study has found a relationship between tracheal sarcomatoid carcinoma and EMT. It has been reported that sarcomas were seen in just 3.8\% of tracheal tumours. ${ }^{13}$ Only three cases of tracheal sarcomatoid carcinoma have been reported. ${ }^{2-4}$ The higher value of $\mathrm{Ki}-67$, the more the cell proliferation and tumour invasion ability. In this case, $22.4 \%$ of Ki-67 expression in epithelial component and $24.0 \%$ in spindle cell component were low compared with median 62\% (range, 20\% to $87 \%$ ) expression in pulmonary pleomorphic carcinoma of 17 patients reported in Japan. ${ }^{14}$ Pleomorphic carcinoma is a subtype of sarcomatoid carcinoma, and is defined as an epithelial tumour including more than $10 \%$ spindle and/or giant cells. ${ }^{15}$ This case was compatible with the characteristics of pleomorphic carcinoma. Several reports identify complete resection as the first choice for treatment of primary tracheal tumours. ${ }^{16}$
However, as the patient had undergone CRT for laryngeal cancer, we considered surgical resection to have a higher risk of complications including necrosis of the trachea and ruptured suture. We thus selected RT for this patient. However, the effect of RT can be considered to be limited. The Netherlands Cancer Registry reports median survival of 91 months in cases of resection without RT, 82 months in cases of resection with RT, 11 months for patients who underwent only RT and 3 months for patients who did not receive either therapy. ${ }^{17}$ We should note that this result included cases of palliative RT, but it is clear that $\mathrm{RT}$ is inferior to resection. We should consider other treatment

\section{Patient's perspective}

I only remember the moment before I was connected to the ventilator. I will do what I can to ensure the success of my treatment and rehabilitation.

\section{Learning points}

- We should consider tracheal tumour as a differential diagnosis in patients with symptoms such as shortness of breath and wheezing similar to bronchial asthma or chronic obstructive pulmonary disease.

- We should add tracheal tumours in the list of differential diagnosis in post-irradiated cases with tumour of larynx, hypopharynx, and supraglottic region.

- We should treat cases of such difficult malignant tumour with specialists through tumour board meeting.

- There have been few reports of primary tracheal tumours related to epithelial-mesenchymaltransition, and we need to investigate further.

- We need to develop effective treatments for tracheal tumours that are difficult to resect. 
options for unresectable tracheal tumours, and we need to follow-up this case carefully.

Contributors HS treated the patient and wrote this case report. NU and TS made a pathological diagnosis of the patient. Makoto Maemodo provided guidance for this case report.

Funding The authors have not declared a specific grant for this research from any funding agency in the public, commercial or not-for-profit sectors.

Competing interests None declared.

Patient consent for publication Obtained.

Provenance and peer review Not commissioned; externally peer reviewed.

Open access This is an open access article distributed in accordance with the Creative Commons Attribution Non Commercial (CC BY-NC 4.0) license, which permits others to distribute, remix, adapt, build upon this work non-commercially, and license their derivative works on different terms, provided the original work is properly cited and the use is non-commercial. See: http://creativecommons.org/ licenses/by-nc/4.0/.

\section{REFERENCES}

1 Ellman P, Whittaker H. Primary carcinoma of the trachea. Thorax 1947;2:153-62.

2 Jang S-H, Cho HD, Lee J-H, et al. Sarcomatoid carcinoma in the trachea: a case report and literature review. Thorac Cancer 2017:8:278-82.

3 Aksu K, Aktaş Z, Aksu F, et al. Spindle cell sarcomatoid carcinoma: first case reported in the trachea. Tuberk Toraks 2009:57:337-41.

4 Gurria JP, De Acosta DM, Hafezi N, et al. Spindle cell sarcomatoid carcinoma of the trachea: first case report of surgical resection. J Cardiothorac Surg 2016;11:128.
5 Pastushenko I, Brisebarre A, Sifrim A, et al. Identification of the tumour transition states occurring during EMT. Nature 2018;556:463-8.

6 Sherani K, Vakil A, Dodhia C, et al. Malignant tracheal tumors: a review of current diagnostic and management strategies. Curr Opin Pulm Med 2015;21:322-6.

7 Braman SS. Endobronchial metastasis. Arch Intern Med 1975;135:543-7.

8 Thompson EW, Nagaraj SH. Transition states that allow cancer to spread. Nature 2018;556:442-4

9 Hollier BG, Evans K, Mani SA. The epithelial-to-mesenchymal transition and cancer stem cells: a coalition against cancer therapies. J Mammary Gland Biol Neoplasia 2009;14:29-43.

10 Moreno-Bueno G, Portillo F, Cano A. Transcriptional regulation of cell polarity in EMT and cancer. Oncogene 2008;27:6958-69.

11 Sugimoto R, Uesugi N, Yamada N, et al. Sarcomatoid change associated with epithelial-mesenchymal transition in mucinous tubular and spindle cell carcinoma of the kidney: a case report. Int J Clin Exp Pathol 2019;12:2767-71.

12 Sung $\mathrm{CO}$, Choi H, Lee K-W, et al. Sarcomatoid carcinoma represents a complete phenotype with various pathways of epithelial mesenchymal transition. J Clin Pathol 2013;66:601-6.

13 Madariaga MLL, Gaissert HA. Overview of malignant tracheal tumors. Ann Cardiothorac Surg 2018;7:244-54.

14 Kaira K, Horie Y, Ayabe E, et al. Pulmonary pleomorphic carcinoma: a clinicopathological study including EGFR mutation analysis. J Thorac Oncol 2010;5:460-5.

15 Travis WD, Brambilla E, Nicholson AG, et al. The 2015 World Health organization classification of lung tumors: impact of genetic, clinical and radiologic advances since the 2004 classification. J Thorac Oncol 2015:10:1243-60.

16 Urdaneta Al, Yu JB, Wilson LD, et al. Population based cancer registry analysis of primary tracheal carcinoma. Am J Clin Oncol 2011:34:32-7.

17 Honings J, van Dijck JAAM, Verhagen AFTM, et al. Incidence and treatment of tracheal cancer: a nationwide study in the Netherlands. Ann Surg Oncol 2007;14:968-76.

Copyright 2020 BMJ Publishing Group. All rights reserved. For permission to reuse any of this content visit https://www.bmj.com/company/products-services/rights-and-licensing/permissions/ BMJ Case Report Fellows may re-use this article for personal use and teaching without any further permission.

Become a Fellow of BMJ Case Reports today and you can:

- Submit as many cases as you like

- Enjoy fast sympathetic peer review and rapid publication of accepted articles

- Access all the published articles

- Re-use any of the published material for personal use and teaching without further permission

\section{Customer Service}

If you have any further queries about your subscription, please contact our customer services team on +44 (0) 2071111105 or via email at support@bmj.com.

Visit casereports.bmj.com for more articles like this and to become a Fellow 